\title{
4th National In-patient Diabetes Conference, Royal Society of Medicine
}

\author{
Dr Paul Grant reports from the Royal Society of Medicine, London on the \\ 4th National In-patient Diabetes Conference, 28th January 2015
}

In-patient diabetes services are still in their relative infancy, being a mixture of informal ad-hoc advice provision, dedicated specialist nurse allocation where possible and, in some enlightened areas, a specifically commissioned multi-disciplinary team approach with clear Consultant Diabetologist input. Practice varies hugely across the board, so it was very interesting and enjoyable to attend the National In-patient Diabetes Conference in January, now in its 4th year, to hear about the latest innovations and developments in this exciting sub-specialty.

The conference covered a great amount, touching on the structure, systems and philosophy of in-patient diabetes care. Firstly we heard from each of the 4 nations within the UK on the pressing issues and difficulties with providing decent in-patient services. Colin Perry from Glasgow spoke about the work of Health Improvement Scotland and the 'Quality Improvement Hub', which has supported a national approach to improving key aspects of diabetes care in Scottish hospitals, focussing on hypoglycaemia management, insulin prescribing and footcare.

Stella George from Hertfordshire (who was recently involved in the latest JBDS insulin sliding scale guidance) gave a presentation on the award winning in-patient diabetes project in her local trust, which used funding from CQUIN (Commissioning for Quality and Innovation) monies to support the formation of the Diabetes Outreach Team (DOT) which aimed to provide seamless care for patients coming into hospital. This was a clear example of using local NADiA data to successfully act as a lever with local commissioners.

There then followed a series of presentations on a variety of projects from around the UK designed to show innovations in patient care, which included audits of lower extremity amputations, a systematised approach to flagging up the presence of patients with diabetes in the hospital and an interesting talk by Rajesh Rajendran on the effect of the 'Killing Season' (also known as junior doctor changeover in August) on glycaemic control in inpatients.

The afternoon was rounded off by a series of workshops, several of which sparked a great deal of debate. These included a discussion of inpatient glycaemic targets and when to intervene by Khetan Dhatariya, and how to support developments in inpatient diabetes services by Alistair Lumb, Rustam Rea and Garry Tan from Oxford.

Overall, this was a very useful and relevant meeting and demonstrated that the same problems are occurring frequently and that pockets of good practice can be spread around. The overriding issue of concern is that of support for the continuance of NADiA. Following a year in which this important national audit was not supported, hopefully funding will be back on track for 2015.

\section{Dr Paul Grant E-mail: editorpg@bjdvd.com} http://dx.doi.org/10.15277/bjdvd.2015.008 $\mathrm{Br} J$ Diabetes Vasc Dis 2015;15:41

\section{THE BRITISH JOURNAL OF Vascular Disease}

\section{Sign up for electronic table of contents}

The Journal of the Association of British Clinical Diabetologists

To receive eTOC\# alerts please go to http://bjdvd.co.uk/index.php/bjdvd/user/register, or register via www.bjdvd.com 